\title{
SEX DIFFERENCES AND ESTROUS CYCLE VARIATIONS IN AMPHETAMINE-ELICITED ROTATIONAL BEHAVIOR
}

\author{
JILL B. BECKER *, TERRY E. ROBINSON and KIMBERLY A. LORENZ \\ Department of Psychology and Neuroscience Laboratory, University of Michigan, 1103 E. Huron, Ann Arbor, MI 48109, U.S.A.
}

Received 23 September 1981, revised MS received 15 January 1982, accepted 4 February 1982

J.B. BECKER, T.E. ROBINSON and K.A. LORENZ, Sex differences and estrous cycle variations in amphetamine-elicited rotational behavior, European J. Pharmacol. 80 (1982) 65-72.

The experiments reported here were designed to determine if there are sex- and/or estrous cycle-dependent differences in amphetamine (AMPH)-elicited rotational behavior in unlesioned rats. Whole brain or striatal levels of AMPH produced by systemic administration of the drug were also measured. At all doses tested (1.0-10.0 mg/kg) systemic administration of AMPH resulted in significantly higher brain levels of AMPH in females than in males. A systemic dose was then calculated which produced equivalent brain levels of AMPH in males and females. Even with equivalent brain levels of AMPH, males produced significantly fewer net rotations than females in estrus, diestrus 2, or proestrus. In female rats the brain levels of AMPH produced by systemic administration did not vary with the estrous cycle. However, the amount of AMPH-elicited rotational behavior did. On the day of estrus, females produced significantly more net rotations than they did $24 \mathrm{~h}$ later, on the day of diestrus $\mathrm{l}$. It is suggested that sex and estrous cycle dependent differences in rotational behavior may be due to the direct or indirect modulation of mesostriatal dopamine activity by gonadal steroid hormones.

Sex differences Rotational behavior Amphetamine Estrous cycle Dopamine Striatum

\section{Introduction}

Sex differences have been reported in the behavioral effects of amphetamine (AMPH) in rats. Female rats show more intense and prolonged stereotypy and greater locomotor activity in response to AMPH than do male rats (Meyer, 1977; Beatty and Holzer, 1978; Schneider and Norton, 1979; Savageau and Beatty, 1981). Female rats also exhibit a greater amount of AMPH-induced rotational behavior than do males (Robinson et al., 1980; Brass and Glick, 1981). However, a confounding variable in all of these previous studies is that sex differences exist in the metabolism of AMPH (Kato, 1974). AMPH is metabolized more rapidly in male rats than in females. Therefore, when males and females receive the same systemic dose of AMPH, brain levels are significantly lower in males than in females (Meyer and Lytle, 1978).

* To whom all correspondence should be addressed: Neuroscience Bldg., 1103 E. Huron St., Ann Arbor, MI 48109, U.S.A.
Some authors have attempted to compensate for the sex difference in AMPH metabolism by demonstrating that behavioral sex differences persist even when male rats are given a much larger dose of AMPH than females (Brass and Glick, 1981; Schneider and Norton, 1979). However, this does not enable one to directly compare the behavioral effects of AMPH in males and females. To make such a comparison we first empirically determined systemic doses of AMPH which produce equivalent brain : ?vels of AMPH in males and females. We were then able to study sex- and estrous cycle-related differences in AMPH-elicited rotational behavior. In this study we report that when male and female rats have equivalent brain concentrations of AMPH, females show significantly more net rotations than do males. In addition, while there are no estrous cycle-dependent differences in brain levels of AMPH, the amount of rotational behavior elicited by AMPH fluctuates with the estrous cycle in female rats. 


\section{Materials and methods}

\subsection{Subjects}

Adult male and female Holzman rats (Holtzman Co., Madison, WI) were maintained on a reversed 14:10, light: dark cycle (lights off at 9:00 a.m., on at 7:00 p.m.) with food and water ad libitum. Females were monitored for stage of estrous cycle by daily vaginal smear examination for at least 8 days immediately prior to an experiment and only regularly cycling females were used. Estrus was defined by the presence of cornified cells in the vaginal smear, which correlates with behavioral receptivity. Other days of the cycle were defined by the morphology of cells in the smear and the last occurrence of estrus. Males were also handled daily.

\subsection{Materials}

All materials were reagent grade except for the methanol which was HPLC grade. $\left[{ }^{3} \mathrm{H}\right] \mathrm{d}$-amphetamine sulfate $(9-20.4 \mathrm{Ci} / \mathrm{mmol})$ was obtained from New England Nuclear, p-hydroxynorephedrine [p-OHNE;DL- $\alpha$-(1-Aminoethyl)-p-hydroxybenzylalcoholhydrochloride] from Aldrich Chemical Co., and p-hydroxyamphetamine (p-OHA) was from Smith, Kline, and French (Philadelphia, PA).

\subsection{Concentration of amphetamine in whole brains of male and female rats}

Animals were placed in an automatic rotometer similar to that described by Greenstein and Glick (1975). After a $15 \mathrm{~min}$ habituation period, each rat received an intraperitoneal (i.p.) injection of damphetamine sulfate $(0.625-10 \mathrm{mg} / \mathrm{kg})$ which also contained $17 \mu \mathrm{Ci} / \mathrm{kg}\left[{ }^{3} \mathrm{H}\right] \mathrm{d}$-amphetamine sulfate and was replaced in the rotometer. At 5,30 or 60 min after the AMPH injection, animals were removed from the rotometer and killed by decapitation. Whole brain levels of AMPH were determined according to the method of Gropetti and Costa (1969). Briefly, this method involves the extraction of the radioactively labeled compounds (AMPH and its metabolites p-OHA and p-OHNE) into $0.4 \mathrm{~N}^{-\mathrm{HClO}_{4}}$ and the subsequent separation of AMPH from its metabolites on Dowex-50-X4 ion exchange columns. Two $\mathrm{ml}$ of the effluent fraction in which AMPH was eluted were added to $10 \mathrm{ml}$ ACS scintillation cock tail (Amersham Corp.) and samples counted on a Beckman LS 8100 scintillation counter. Standards of known concentrations were prepared from the injection solution and added to brains of control rats (uninjected) to generate a standard curve for each assay.

Brain levels of AMPH were determined for the following groups: (a) Females from each of the 4 days of the estrous cycle (estrus, diestrus 1, diestrus 2 and proestrus). Eight animals from each group were killed at 5,30 and $60 \mathrm{~min}$ following the injection of $1.25 \mathrm{mg} / \mathrm{kg}$ AMPH. (b) Doseresponse curves were generated for males and estrous females. Males received the following doses and were killed at 30 or 60 min after injection: $1.0 \mathrm{mg} / \mathrm{kg}(\mathrm{n}=6), 1.25 \mathrm{mg} / \mathrm{kg}(\mathrm{n}=8), 1.56 \mathrm{mg} / \mathrm{kg}$ $(\mathrm{n}=8), 1.8 \mathrm{mg} / \mathrm{kg}(\mathrm{n}=6)$ and $10 \mathrm{mg} / \mathrm{kg}(\mathrm{n}=6)$. For the dose of $1.56 \mathrm{mg} / \mathrm{kg}$ animals $(\mathrm{n}=8)$ were killed $5 \mathrm{~min}$ after injection as well and at 6.0 $\mathrm{mg} / \mathrm{kg}$ animals $(\mathrm{n}=6)$ were killed $30 \mathrm{~min}$ after injection only. Estrous females received the following doses and were killed at 30 and $60 \mathrm{~min}$ following injection: $0.625 \mathrm{mg} / \mathrm{kg}(\mathrm{n}=6), 1.0 \mathrm{mg} / \mathrm{kg}$ $(\mathrm{n}=6), 5 \mathrm{mg} / \mathrm{kg}(\mathrm{n}=6)$ and $10 \mathrm{mg} / \mathrm{kg}(\mathrm{n}=6)$. In all cases the number of subjects indicated is the number used at each time period for a given dose.

\subsection{Concentration of amphetamine in the striatum of male and female rats}

To confirm that whole brain levels of AMPH are indicative of striatal AMPH concentrations, left and right striatal AMPH concentrations were determined in males and estrous females. Animals were placed in an automated rotometer as before. After a 15 min habituation period, females $(n=6)$ were injected with $1.25 \mathrm{mg} / \mathrm{kg}$ per ml AMPH containing $\left.150 \mu \mathrm{Ci} / \mathrm{ml} \mathrm{[}{ }^{3} \mathrm{H}\right] \mathrm{d}$-amphetamine sulfate and males $(\mathrm{n}=12)$ were injected with $1.56 \mathrm{mg} / \mathrm{kg}$ per $\mathrm{ml} \mathrm{AMPH}$, containing $150 \mu \mathrm{Ci} / \mathrm{ml}\left[{ }^{3} \mathrm{H}\right] \mathrm{d}-$ amphetamine sulfate. These doses were chosen since whole brain determinations indicated that these doses produced equivalent brain levels of 
AMPH in males and females. Animals were removed from the rotometers and killed by decapitation $30 \mathrm{~min}$ after the injection of AMPH. The brain was then rapidly removed, left and right striata were dissected out separately and each homogenized in $2 \mathrm{vol}(\mathrm{w} / \mathrm{v}) 0.05 \mathrm{~N} \mathrm{HClO}_{4}$ containing $50 \mu \mathrm{g} / \mathrm{mg}$ of pOHNE, $50 \mu \mathrm{g} / \mathrm{ml} \mathrm{pOHA}$ and $4 \times 10^{-4} \mathrm{M} \mathrm{NaHSO}_{4}$. Samples were then centrifuged at $3500 \times g \times 45 \mathrm{~min}$ and stored on ice for up to $24 \mathrm{~h}$ until assayed.

High performance liquid chromatography (HPLC) was used to separate $\left[{ }^{3} \mathrm{H}\right] \mathrm{AMPH}$ from its metabolites with electrochemical detection (EC) used to verify the separation of AMPH from its metabolites. The HPLC system employed a Whatman ODS- 3 reverse phase $\mathrm{C}-18$ column and a LC-4 amperometric detector with a glassy carbon electrode (BioAnalytical Systems, Lafayette, IN). The mobile phase was composed of citric acid (12.61 g/l), $\mathrm{Na}_{2} \mathrm{HPO}_{4}(10.72 \mathrm{~g} / \mathrm{l})$ and $45 \%$ methanol and was pumped at $600 \mu \mathrm{l} / \mathrm{min}$. The detector potential was set at $+0.95 \mathrm{~V}$ vs. a $\mathrm{Ag} / \mathrm{AgCl}$ reference electrode. The sample loop volume was $100 \mu 1$ and $50 \mu 1$ samples were injected onto the column. Since AMPH is not electrochemically active, it was necessary to establish the quantity of AMPH by other methods. A sample of $\left[{ }^{3} \mathrm{H}\right] \mathrm{AMPH}$ was injected onto the column to establish when the peak of radioactivity eluted. Thereafter, the fraction corresponding to the peak $(1.8 \mathrm{ml})$ was collected and counted in $10 \mathrm{ml} \mathrm{ACS}$ scintillation cocktail.

Both pOHA and pOHNE show some electrochemical activity. We took advantage of this property of these AMPH metabolites to establish unequivocably that the fraction we collected for quantification of AMPH by radioactivity did not contain any metabolite contamination. By adding a known amount of the metabolites to the tissue, these metabolites were easily detected at 100 $\mathrm{nA} / \mathrm{V}$. Under the conditions described above, the p-OHNE peak eluted at $4.5 \mathrm{~min}, \mathrm{p}-\mathrm{OHA}$ at 5.5 min and AMPH at $9.5 \mathrm{~min}$. A standard curve prepared from the injection solution and added to untreated brain tissue was run for each assay.
2.5. Amphetamine-induced rotational behavior in male and female rats

As described above, each animal was allowed a 15 min habituation period in the rotometer, before it was injected with AMPH. Following the injection, rotational behavior was recorded for $5(\mathrm{n}=$ 24), $30(n=16)$ or $60(n=8) \mathrm{min}$. The rotometers used in this study were interfaced with a microprocessor which monitored every $1 / 4$ turn $\left(90^{\circ}\right)$ made to the right or left during each $5 \mathrm{~min}$ interval. From these data the following were calculated. (a) Net rotations: A rotation consists of 4 consecutive $1 / 4$ turns in the same direction. Net rotations are the number of total rotations in the dominant direction minus those in the non-dominant direction. When given AMPH most rats turn in one predominant direction (Glick et al., 1977). (b) $E x$ tra 1/4 turns: The number of total 1/4 turns to the left and right minus the number of total rotations in both directions times 4 (i.e. the number of $1 / 4$ turns which do not contribute to rotations).

These data were obtained for all animals tested. However, the behavioral data is presented only for those groups which did not differ in brain concentrations of AMPH. These were the 4 female groups (estrus, diestrus 1, diestrus 2 and proestrus) tested with $1.25 \mathrm{mg} / \mathrm{kg} \mathrm{AMPH}$ and males tested with $1.56 \mathrm{mg} / \mathrm{kg} \mathrm{AMPH}$.

\section{Results}

\subsection{Brain levels of AMPH in female rats across the estrous cycle}

As table 1 indicates, there were no estrous cycle dependent differences in brain levels of AMPH ( $\mu \mathrm{g} \mathrm{AMPH} / \mathrm{g}$ brain) at $5(\mathrm{~F}=0.84), 30(\mathrm{~F}=0.49)$ or $60(\mathrm{~F}=0.82) \mathrm{min}$ following the i.p. injection of $1.25 \mathrm{mg} / \mathrm{kg}$ AMPH. Within $5 \mathrm{~min}$ of AMPH injection, brain AMPH levels were $82 \pm 6 \%$ of the maximum levels, which were measured $30 \mathrm{~min}$ after injection. One hour after injection, AMPH levels were significantly less $(t=8.99, P<0.0001)$ than at $30 \mathrm{~min}$. 


\section{TABLE 1}

Average $( \pm$ S.E.) whole brain levels of amphetamine ( $\mu \mathrm{g}$ AMPH $/ g$ brain) at 3 points in time after an i.p. injection of $1.25 \mathrm{mg} / \mathrm{kg} \mathrm{d}$-amphetamine sulfate in female rats across the estrous cycle ( $n=8 /$ group)

\begin{tabular}{llll}
\hline & $5 \mathrm{~min}$ & $30 \mathrm{~min}$ & $60 \mathrm{~min}$ \\
\hline Diestrus 1 & $1.40 \pm 0.11$ & $1.51 \pm 0.18$ & $0.93 \pm 0.08$ \\
Diestrus 2 & $1.11 \pm 0.12$ & $1.68 \pm 0.16$ & $0.83 \pm 0.07$ \\
Proestrus & $1.17 \pm 0.15$ & $1.48 \pm 0.08$ & $0.92 \pm 0.10$ \\
Estrus & $1.33 \pm 0.20$ & $1.49 \pm 0.07$ & $0.77 \pm 0.07$ \\
\hline
\end{tabular}

\subsection{Sex differences in whole brain $A M P H$ con- centrations}

When males and females were given an equal dose of AMPH systemically, males had significantly lower whole brain concentrations of AMPH for all doses tested (1.0-10.0 mg/kg; table 2). By an examination of the dose-response curves we estimated that if males were injected with 1.56 $\mathrm{mg} / \mathrm{kg}$ of AMPH they should have whole brain levels of AMPH comparable to those in females

\section{TABLE 2}

Average $( \pm$ S.E.) whole brain levels of amphetamine in male and female rats after administration of various i.p. doses of d-amphetamine sulfate.

\begin{tabular}{lrll}
\hline Dose & $\mathrm{n}$ & \multicolumn{2}{l}{ Brain levels amphetamine $(\mu \mathrm{g} / \mathrm{g})$} \\
\cline { 3 - 4 } & & $30 \mathrm{~min}$ & $60 \mathrm{~min}$ \\
\hline Males & & & \\
1.0 & 6 & $0.99 \pm 0.09^{* *}$ & $0.45 \pm 0.04^{* * *}$ \\
1.25 & 8 & $1.07 \pm 0.10^{*}$ & $0.56 \pm 0.07^{*}$ \\
1.56 & 8 & $1.45 \pm 0.07$ & $0.57 \pm 0.04$ \\
1.80 & 6 & $1.98 \pm 0.17$ & $0.83 \pm 0.09$ \\
6.0 & 6 & $8.72 \pm 0.49$ & no data \\
10.0 & 7 & $13.20 \pm 0.83 *$ & $5.84 \pm 0.24 * * *$ \\
Females & & & \\
0.625 & 6 & $0.71 \pm 0.03$ & $0.52 \pm 0.06$ \\
1.0 & 6 & $1.30 \pm 0.10$ & $0.68 \pm 0.02$ \\
1.25 & 32 & $1.54 \pm 0.06$ & $0.86 \pm 0.04$ \\
5.0 & 6 & $7.69 \pm 0.44$ & $3.43 \pm 0.18$ \\
10.0 & 7 & $15.15 \pm 0.62$ & $8.84 \pm 0.67$ \\
& & &
\end{tabular}

Differs from females given equivalent systemic dose, Student's t-test for independent groups, ${ }^{*} \mathrm{P}<0.05,{ }^{* *} \mathrm{P}<0.02,{ }^{* * *} \mathrm{P}<$ 0.001 , respectively. injected with $1.25 \mathrm{mg} / \mathrm{kg}$ of AMPH. We therefore injected male rats with $1.56 \mathrm{mg} / \mathrm{kg}$ of $\mathrm{AMPH}$ (i.p.), measured whole brain concentrations of AMPH at 5, 30 or 60 min after the injection, and compared these levels of AMPH to those observed in female rats from across the estrous cycle (see table 1 for the AMPH levels in females and table 2 for the levels in males). A one-way analysis of variance at each time interval revealed that at 5 and 30 min post-injection the whole brain levels of AMPH in males given $1.56 \mathrm{mg} / \mathrm{kg}$ of AMPH did not differ from those in estrus, diestrus 1, diestrus 2 or proestrus females given $1.25 \mathrm{mg} / \mathrm{kg}$ of AMPH $(F=0.97$ and 0.53 respectively). At $60 \mathrm{~min}$ postinjection whole brain levels of AMPH in males did not differ from estrous females, but they were significantly lower than in the other 3 female groups $(\mathrm{F}=3.74, \mathrm{P}<0.01$; Tukey A-tests, $\mathrm{P}<$ 0.05; Winer, 1971).

\subsection{Amphetamine concentration in striatum}

Thirty min after an i.p. injection the concentration of AMPH was measured in the left and right striatum of male rats given $1.56 \mathrm{mg} / \mathrm{kg}$, and in estrous females given $1.25 \mathrm{mg} / \mathrm{kg}$ (see table 3 ). Comparisons ( $\mathrm{t}$-tests) between males and females revealed no significant differences in striatal AMPH concentration. AMPH levels in the left striatum did not differ from those in the right striatum, and levels in the striatum contralateral to the dominant direction of rotation did not differ from those in the ipsilateral striatum, in either males or females (paired t-test).

\subsection{Estrous cycle variations in AMPH-induced rota- tional behavior}

Fig. 1 shows the number of net rotations made by female rats in different stages of the estrous cycle during the first 30 min after AMPH administration. The number of net rotations varied with the stage of the estrous cycle $(\mathrm{F}=2.65, \mathrm{P}<0.057)$. A planned comparison revealed that estrous females made significantly more net rotations than did females in diestrus 1 (Tukey $\mathbf{A}, \mathbf{P}<0.05$ ). This difference in rotational behavior occurred in the absence of any estrous cycle dependent differences 
TABLE 3

Average ( \pm S.E.) amphetamine concentration ( $\mu \mathrm{g} \mathrm{AMPH} / \mathrm{g}$ striatum) in the left vs. right and contralateral vs. ipsilateral striatum of male rats injected with $1.56 \mathrm{mg} / \mathrm{kg}$ AMPH (i.p.) and females injected with $1.25 \mathrm{mg} / \mathrm{kg}$ AMPH.

\begin{tabular}{lrlllll}
\hline & $\mathrm{n}$ & Left & Right & $\mathrm{n}$ & Contralateral * & Ipsilateral \\
\hline Males & 12 & $1.46 \pm 0.10$ & $1.48 \pm 0.09$ & 9 & $1.51 \pm 0.11$ & $1.50 \pm 0.10$ \\
Females & 6 & $1.29 \pm 0.10$ & $1.32 \pm 0.10$ & 6 & $1.32 \pm 0.09$ & $1.29 \pm 0.11$
\end{tabular}

* Contralateral and ipsilateral are relative to the dominant direction of rotation; 3 male rats made no net rotations and were excluded from the contralateral/ipsilateral analysis.

in brain levels of AMPH $(F=0.491)$; see fig. 1$)$. During the second $30 \mathrm{~min}$ period after AMPH administration the number of net rotations continued to vary across the estrous cycle $(F=2.99$, $P<0.05$ ). During this time interval females in estrus and diestrus 2 made significantly more net rotations than did diestrous 1 females (Tukey A, $\mathrm{P}<0.05$ ).

Interestingly, the low level of rotational behavior observed in diestrous 1 females was not due to a generalized decrement in the behavioral response to AMPH. Diestrous 1 females made as many extra quarter turns $(260 \pm 46 ; \bar{X} \pm$ S.E. $)$ as did estrous $(266 \pm 32)$ or diestrous $2(254 \pm 25)$ females. However, female rats in proestrus made significantly fewer extra quarter turns $(158 \pm 30)$ than

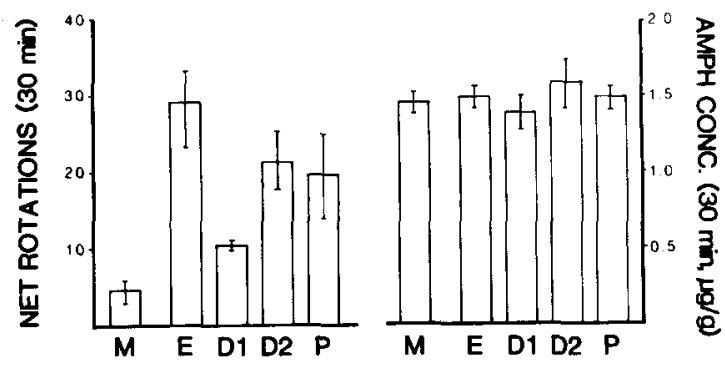

Fig. 1. Rotational behavior and whole brain concentrations of AMPH in male and female rats at different stages of the estrous cycle. Males (M) received $1.56 \mathrm{mg} / \mathrm{kg}$ AMPH (i.p.) and females $(E=$ estrus,$\quad D 1=$ diestrus $1, D 2=$ diestrus $2, \quad P=$ proestrus) $1.25 \mathrm{mg} / \mathrm{kg}$ of AMPH. On the left the mean ( \pm S.E.) number of net rotations made during $30 \mathrm{~min}$ following the AMPH injection are plotted ( $n=16$ for each group). On the right the mean ( \pm S.E.) whole brain concentrations of AMPH ( $\mu \mathrm{g}$ AMPH $/ \mathrm{g}$ brain) $30 \mathrm{~min}$ after the AMPH injection are shown ( $n=8$ for each group). See the text for a description of these data. did diestrous 1 or diestrous 2 females $(F=3.42$, $\mathrm{P}<0.02$; Tukey $\mathrm{A}$ tests, $\mathrm{P}<0.05-0.01)$. During the second 30 min interval after AMPH administration there were no significant differences in the number of extra quarter turns made by the four female groups $(F=0.781)$. Extra quarter turns have been reported to be positively correlated, and net rotations negatively correlated, with the locomotor activity in an open field situation (Greenstein and Glick, 1975).

\subsection{Sex differences in $A M P H$-induced rotational behavior}

Fig. 1 shows that when male rats are injected with $1.56 \mathrm{mg} / \mathrm{kg}$ of AMPH and females with 1.25 $\mathrm{mg} / \mathrm{kg}$ there are significant sex differences in rotational behavior $(F=5.07, P<0.005)$. These behavioral sex differences occur in the absence of differences in brain levels of AMPH. Pairwise comparisons (Tukey A) showed that males made significantly fewer net rotations in $30 \mathrm{~min}$ than did females in estrus $(\mathrm{P}<0.01)$, diestrus $2(\mathrm{P}<0.01)$ or proestrus $(\mathrm{P}<0.05)$. There is no statistical difference between males and diestrous 1 females. Males also made significantly fewer extra quarter turns $(135 \pm 17)$ than estrous, diestrous 1 or diestrous 2 females $(F=3.42$; Tukey $A$ tests, $P<0.05$ -0.01 ), but did not differ from proestrous females. This sex difference in rotational behavior is not peculiar to the doses of AMPH used in the above experiment. In an independent experiment by Dianne Camp, in our laboratory, the AMPH-induced rotational behavior of estrous female rats given $0.85 \mathrm{mg} / \mathrm{kg}$ of AMPH was compared to that of littermate male rats given $1.2 \mathrm{mg} / \mathrm{kg}$. These doses 


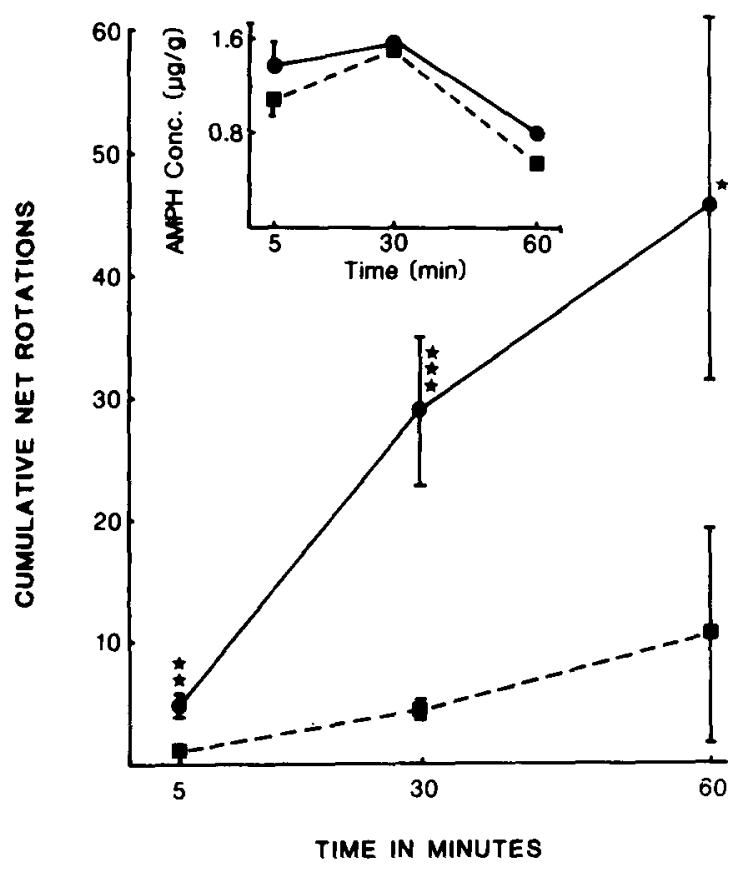

Fig. 2. The mean ( \pm S.E.) number of cumulative net rotations produced by AMPH in estrous females given $1.25 \mathrm{mg} / \mathrm{kg}$ and males given $1.56 \mathrm{mg} / \mathrm{kg}$ during the hour immediately following AMPH administration. At $5 \mathrm{~min} n=24$, at $30 \mathrm{~min} n=16$ and at $60 \mathrm{~min} n=8$. Females made significantly more net rotations than males at all times intervals $(\star P<0.05, \star \star P<0.01$, $\star \star \star \mathrm{P}<0.001$ ). The insert shows the brain levels of AMPH at 5,30 and $60 \mathrm{~min}$ post-injection in these same animals. The brain levels of AMPH in the males did not differ from those of the estrous females at any time interval.

of AMPH should produce equivalent brain levels of AMPH in male and female rats. Camp found that over the $60 \mathrm{~min}$ test period estrous females $(\mathrm{n}=38)$ made significantly more net rotations $(125.9 \pm 12.4)$ than did males $(53.9 \pm 7.4 ; n=39$; $\mathrm{t}=5.0, \mathrm{P}<0.001$ ).

Finally, fig. 2 shows that the sex difference in rotational behavior is present at all time intervals following AMPH administration. Estrous females given $1.25 \mathrm{mg} / \mathrm{kg}$ of AMPH and males given 1.56 $\mathrm{mg} / \mathrm{kg}$ do not differ in whole brain AMPH levels at 5,30 or $60 \mathrm{~min}$ post-injection (see insert, fig. 2). However, the estrous females did make significantly more net rotations than did male rats at 5 , 30 and $60 \mathrm{~min}$ post-injection (Tukey $\mathrm{A}$ tests, $\mathrm{P}<$ 0.05 ).

\section{Discussion}

In the study reported here we found that behavior elicited by the systemic administration of AMPH fluctuated with the stage of the estrous cycle in female rats. Specifically, females in diestrus 1 made significantly fewer net rotations than females in diestrus 2 or estrus. During the first 30 min after AMPH was injected, females in proestrus showed less general activity, as measured by extra 1/4 turns, than did females in diestrus 1 or diestrus 2. These behavioral differences were not due to differences in the uptake of AMPH into the brain since brain levels of AMPH did not vary with the estrous cycle.

It is thought that the rotational behavior observed in unlesioned rats treated with AMPH is due to an endogenous asymmetry in the nigrostriatal dopamine (DA) system (Glick et al., 1977; Jerussi and Glick, 1974). Therefore, the finding of estrous cycle related differences in rotational behavior suggests that a hormone (or hormones) which fluctuates with the estrous cycle may modulate nigrostriatal DA activity. Estrogen and progesterone have been implicated in this regard. For example, estrous cycle dependent fluctuations have been reported in the AMPH-stimulated release of DA from striatal tissue in vitro (Becker and Ramirez, 1981). AMPH-stimulated DA release is hormonally dependent in female rats. Ovariectomy severely attenuates this striatal DA release and treatment with estrogen followed by progesterone will reinstate the release when striatal tissue is obtained $4 \mathrm{~h}$ after progesterone administration (Becker and Ramirez, 1981). Estrous cycle dependent fluctuations have also been found in striatal DA turnover, as indicated by homovanillic acid (HVA) levels (Jori and Cechetti, 1973), and in striatal DA concentrations (Crowley et al., 1978a).

The time course of the effects of gonadal steroids on striatal DA activity may be critical for an eventual understanding of the interactions involved. Striatal DA activity appears to be lowest on the day of proestrus, as indicated by a depression in AMPH-stimulated DA release, low DA turnover, and high concentrations. On the day of estrus there is increased DA release and turnover, 
coinciding with a decrease in striatal DA concentrations. Striatal DA activity appears to remain elevated through diestus 1, with AMPH-stimulated DA release and HVA levels still significantly greater than on proestrus (Becker and Ramirez, 1981; Jori and Cecchetti, 1973; Crowley et al., 1978a). However, these studies have all employed animals killed during the 'lights on' period of a standard light:dark cycle, while the behavioral studies reported here were conducted during the 'night' portion of the cycle (see Methods). In preliminary experiments in our laboratory, we have found that when female rats are maintained on a reversed (14:10) light: dark cycle and killed $2 \mathrm{~h}$ after lights off, the AMPH-stimulated DA release from striatal tissue of diestrous 1 females is lower than that of estrous females. This suggests that approximately $24 \mathrm{~h}$ after the endogenous surges of gonadal steroids (Butcher et al., 1974) there is decreased nigrostriatal DA activity as demonstrated by decreased AMPH-stimulated DA release in vitro and fewer AMPH-elicited net rotations in diestrous 1 females. This idea is supported by Gordon (1980) who reports a decrease in apomorphine induced stereotypy $24 \mathrm{~h}$ after estradiol benzoate treatment in ovariectomized rats.

Since the behavioral manifestations of nigrostriatal DA activity must rely on both pre- and postsynaptic events, it may be that ovarian hormones are also modulating DA activity postsynaptically. This idea is supported by reports of estrogeninduced increases in the number of striatal DA receptors (Bédard et al., 1979; Hruska et al., 1980). This estrogen-induced increase in striatal DA receptors is blocked by hypophysectomy suggesting these estrogenic effects may be mediated by the pituitary (Hruska et al., 1980).

It is interesting that the pattern of variation across the estrous cycle in AMPH-induced rotational behavior is very similar to that observed by Robinson et al. (1981) for electrical stimulationinduced rotational behavior. Robinson et al. (1981) found that the contraversive rotational behavior produced by electrical stimulation of the ascending DA fibers is significantly greater on the day of estrus than on diestrus 1 . This suggests that estrous cycle fluctuations in AMPH-induced rotational behavior are not due to a unique interaction between events related to the estrous cycle and AMPH.

We also confirmed previous reports of sex differences in brain levels in AMPH following systemic administration of equivalent doses of AMPH. We expanded the knowledge to include a range of doses from $1-10 \mathrm{mg} / \mathrm{kg}$ AMPH. At all doses tested, females had significantly higher brain levels of AMPH than did males. However, when the dose for the male rats was adjusted to produce brain levels of AMPH equivalent to females receiving $1.25 \mathrm{mg} / \mathrm{kg}$ males continued to exhibit fewer net rotations than did females in estrus, diestrus 2 and proestrus.

The finding that females exhibit greater lateralization in AMPH-induced rotational behavior than do males confirms previous reports (Robinson et al., 1980; Brass and Glick, 1981) and affirms that even with equivalent brain levels of AMPH this sex difference persists. We also find that AMPH stimulates less nonspecific behavioral activity in males than in females suggesting that AMPH is generally less effective in males. These behavioral sex differences may be related to a number of factors. Sex differences have been reported in striatal DA concentrations (Crowley et al., 1978b), in the modulatory effects of gonadal steroids on the in vitro release of striatal DA (Becker and Ramirez, 1981) and in electrically stimulated rotational behavior (Robinson et al., 1981). Therefore, a sex difference in functional activity of striatal DA neurons may underlie the sex differences in rotational behavior. Another consideration is the recent report of a sex difference in the distribution of DA between the 2 hemispheres (Robinson et al., 1980). In female rats DA levels are highest in the striatum contralateral to the dominant direction of rotation (Robinson et al., 1980; Jerussi and Glick, 1976). A similar relationship has not been found in males (Robinson et al., 1980). Therefore, a sex difference in the lateralized distribution of striatal DA may also be related to sex differences in rotational behavior.

In summary, we suggest that (1) sex differences and estrous cycle-dependent fluctuations in behaviors elicited by AMPH are due to differences in the effects of the drug on neural activity, not solely 
on peripheral factors such as drug metabolism; (2) endogenous fluctuations in the levels of female gonadal hormones modulate the functional activity of the mesostriatal DA system; and (3) there are sex differences in the functional activity of the mesostriatal DA system, which may be due to differences in how male vs. female gonadal hormones influence brain DA activity.

\section{Acknowledgements}

We thank Dale Jacknow and Sharon Presty for their assistance, Dianne Camp for the use of some of her data, Marylin Hoy for typing the manuscript and Smith, Kline and French for the gift of p-hydroxyamphetamine. Supported by NINCDS Grant NS16437 and NICHHD Grant HD05997.

\section{References}

Beatty, W.W. and G.A. Holzer, 1978, Sex differences in stereotyped behavior in the rat, Pharmacol. Biochem. Behav. 9. 777.

Becker, J.B. and V.D. Ramirez, 1981, Sex differences in the amphetamine stimulated release of catecholamines from rat striatal tissue in vitro, Brain Res. 204, 361.

Bédard, P.J., P. Langelier, J. Dankova, A. Villeneuve, T. DiPaola, N. Barden, F. Labrie, J.R. Boissier and C. Euvrard, 1979. Estrogens, progesterone and the extrapyramidal system, Adv. Neurol. 24, 411

Brass, C.A. and S.D. Glick, 1981, Sex differences in druginduced rotation in two strains of rats. Brain Res. 223, 229.

Butcher, R.L., W.E. Collins and N.W. Fugo, 1974, Plasma concentration of $\mathrm{LH}, \mathrm{FSH}$, prolactin, progesterone and estradiol-178 throughout the 4-day estrous cycle of the rat, Endocrinol. 94, 1704.

Crowley, W.R., T.L. O'Donohue and D.M. Jacobowitz. 1978a, Changes in catecholamine content in discrete brain nuclei during the estrous cycle of the rat, Brain Res. 147, 315.

Crowley, W.R., T.L. O'Donohue and D.M. Jacobowitz, 1978 b. Sex differences in catecholamine content in discrete brain nuclei of the rat: Effects of neonatal castration or testosterone treatment, Acta Endocrinol. 89, 20.
Glick, S.D., T.P. Jerussi and B. Zimmerberg, 1977, Behavioral and neuropharmacological correlates of nigrostriatal asymmetry in rats, in: Lateralization in the Nervous System, eds. S. Harnad et al. (Academic Press, New York) p. 213.

Gordon, J.H., 1980, Modulation of apomorphine-induced stereotypy by estrogen: time course and dose response, Brain Res. Bull. 5, 679 .

Greenstein, S. and S.D. Glick, 1975, Improved automated apparatus for recording rotation (circling behavior) in rats or mice, Pharmacol. Biochem. Behav. 3, 507.

Gropetti, A. and E. Costa, 1969, Tissue concentrations of p-hydroxynorephedrine in rats injected with d-amphetamine: effect of pretreatment with desipramine, Life Sci. 8, 653.

Hruska, R.E., L.M. Ludmer and E.K. Silbergeld, 1980, Characterization of the striatal dopamine receptor supersensitivity produced by estrogen treatment of male rats. Neuropharmacol. 19, 923.

Jerussi, T.P. and S.D. Glick, 1974, Amphetamine-induced rotation in rats without lesions, Neuropharmacol. 13, 283.

Jori, A. and G. Cecchetti, 1973, Homovanillic acid levels in rat striatum during the oestrus cycle, J. Endocrinol. 58, 341.

Kato, R., 1974, Sex-related differences in drug metabolism. Drug Met. Rev. 3, 1.

Meyer, E., 1977, Age- and sex-related differences in amphetamine-induced locomotor activity, Fed. Proc. 36, 1033.

Meyer, E.M. and L.D. Lytle, 1978, Sex-related differences in the physiological disposition of amphetamine and its metabolites in the rat, Proc. West. Pharmacol. Soc. 21, 313.

Robinson, T.E., J.B. Becker and V.D. Ramirez, 1980, Sex differences in amphetamine-elicited rotational behavior and the lateralization of striatal dopamine in rats. Br. Res. Bull. 5. 539

Robinson, T.E., D.M. Camp and J.B. Becker, 1981, Sex differences and estrous cycle variations in rotational behavior elicited by electrical stimulation of the nigrostriatal dopamine system, Soc. Neurosci. Abstr. 7, 42.

Savageau, M.M. and W.W. Beatty, 1981, Gonadectomy and sex differences in the behavioral responses of amphetamine and apomorphine of rats, Pharmacol. Biochem. Behav. 14. 17.

Schneider, B.F. and S. Norton, 1979. Circadian and sex differences in hyperactivity produced by amphetamine in rats. Physiol. Behav. 22, 47.

Winer, B.J., 1971, Statistical Principles in Experimental Design (McGraw-Hill Book Co., New York). 